\title{
Application of a lattice Boltzmann method combined with a Smagorinsky turbulence model to spatially resolved heat flux inside a refrigerated vehicle
}

\author{
Maximilian Gaedtke ${ }^{\mathrm{a}, \mathrm{b}, *}$, Simon Wachter ${ }^{\mathrm{a}, \mathrm{b}}$, Matthias Rädle ${ }^{\mathrm{c}}$, \\ Hermann Nirschl ${ }^{\mathrm{b}}$, Mathias J. Krause $\mathrm{a}^{\mathrm{a}, \mathrm{b}, \mathrm{d}}$ \\ a Lattice Boltzmann Research Group, Karlsruhe Institute of Technology, Karlsruhe, Germany \\ ${ }^{b}$ Institute for Mechanical Process Engineering and Mechanics, Karlsruhe Institute of Technology, Karlsruhe, Germany \\ c Institute for Process Control and Innovative Energy Conversion, University of Applied Sciences Mannheim, Germany \\ ${ }^{\mathrm{d}}$ Institute for Applied and Numerical Mathematics, Karlsruhe Institute of Technology, Karlsruhe, Germany
}

Keywords:

LBM

Boussinesq approximation

Turbulence

LES

Smagorinsky

OpenLB

\begin{abstract}
A B S T R A C T
In this work the simulation of velocity and temperature distributions inside a refrigerated vehicle is evaluated. For this purpose a 3D double distribution lattice Boltzmann method (LBM) with the Bhatnagar-Gross-Krook (BGK) collision operator is coupled by the buoyancy force calculated with the Boussinesq approximation. This LBM is extended by a Smagorinsky subgrid method, which numerically stabilizes the BGK scheme for low resolutions and high Reynolds and Rayleigh numbers. Besides validation against the two benchmark cases porous plate and natural convection in a square cavity evaluated at resolutions of $y^{+} \approx 2$ for Ra numbers between $10^{3}$ and $10^{10}$, the method and its implementation are tested via comparison with experimental data for a refrigerated vehicle at $R e \approx 53000$.

The aim of the investigation is to provide a deeper understanding of the refrigerated vehicle's insulation processes including its thermal performance under turbulent flow conditions. Therefore, we extend this method by the half lattice division scheme for conjugate heat transfer to simulate in the geometry of a refrigerated vehicle including its insulation walls. This newly developed method combination enables us to accurately predict velocity and temperature distributions inside the cooled loading area, while spatially resolving the heat flux through the insulation walls. We simulate the time dependent heating process of the open door test and validate against measurements at four characteristic velocity and 13 temperature positions in the truck.
\end{abstract}

\section{Introduction}

Global efforts to reduce carbon dioxide emissions as well as prospectively rising prices of fossil fuels lead to continuous development and efficiency improvements of insulation methods. In residential construction, heating energy requirements are progressively minimized by improving building insulation since 1977 [1]. In the sector of refrigerated transports, which usually derive their cooling performance from gas powered refrigeration units in order to maintain the cooling chain of the hauled product, only little attention has been directed to improve efficiency by enhanced insulation. Reasons for this

\footnotetext{
* Corresponding author at: Lattice Boltzmann Research Group, Karlsruhe Institute of Technology, Karlsruhe, Germany.

E-mail address: maximilian.gaedtke@kit.edu (M. Gaedtke).
} 
are complex material requirements which, in addition to the insulation, include static stability, load securing as well as resistance against vibrational stress.

According to Smale [2] most simulations and models for the representation of a velocity and temperature distribution in the field of applied cooling of geometries between 1974 and 2006 have shown low accuracy and large deviations from experimental data. Tabsoba et al. [3] studied the influence of the $\mathrm{k}-\epsilon$ turbulence model against the Reynolds stress model, where they indicated the $\mathrm{k}-\epsilon$ model to fail at the prediction of certain flow characteristics in ventilated enclosures. Ambaw [4] summarized studies on the cooling of harvested food, indicating some progress being made between 2006 and 2013 with the accuracy of the models. With simulations mainly based on Reynolds averaging turbulence models as the k- $\epsilon$ or shear stress transport (SST) model [5-8], he also came to the conclusion, that a clear increase in the accuracy of turbulent 3D simulations within complex cooled geometries compared with experimental data has still to come.

According to James [9] first simulations of the open door tests have been carried out by Tso et al. [10]. Tso's simulated temperatures deviate from experimental recordings by up to $4 \mathrm{~K}$ at a temperature difference of about 26 K. Son [11] showed an approximation to the validation data up to $1.13 \mathrm{~K}$ in the simulation of the velocity and temperature distribution in the interior of a filled warehouse, while a very slow velocity and a temperature difference of just $7 \mathrm{~K}$ was chosen. Hao [12] implemented a constant heat flow over the walls in a cooled container, but no experimental data was analyzed for verification. Akdemir [13] simulated a cold store and reached a relative error of the temperature of $13 \%$ against the validation data while neglecting heat transfer through the walls.

By considering heat transfer through the walls by particular boundary conditions, Hoang [14] showed good agreement in the temperature distribution in the simulation of a filled cooling room, but found averaged relative errors for the velocity distribution of partly compassing $50 \%$. Cardinale [15] simulated a transport container with a similar method, assuming a constant heat conduction coefficient for the walls and a constant outside temperature of $20^{\circ} \mathrm{C}$, revealing deviations in the temperature distribution of at least $3 \mathrm{~K}$ against measurements at temperature differences of about $43 \mathrm{~K}$. A mean relative error of $26 \%$ and $18 \%$ in the prediction of the velocity and temperature fields, respectively, was achieved in the simulation of a cooled shipping container according to Getahun [16].

In conclusion, this strongly suggests two strategies to increase the accuracy of cooled geometry simulations:

(a) replacement of the Reynolds averaging turbulence model with a large eddy turbulence model and

(b) integration of heat transport through the insulation walls.

Although large eddy simulations (LES) predict flow and temperature fields with higher accuracy, they have not been applied to cooled geometry simulations, yet. This is a consequence of fine computational grids needed for LES, leading to high computational effort and challenging mesh generation. To reduce the increased computational cost of the LES, an efficient and scalable Lattice Boltzmann method is used in this study. In addition, LBM utilizes cartesian grids, which greatly simplifies the mesh generation $[17,18]$. Although (a) might not be absolutely necessary for the geometry and operation setup used in this study, it will be in upcoming studies, where more complex geometries with resolved cargo and spatially different insulation materials are considered. Up to now, modeling of the wall's heat transfer was restricted to spatially constant heat flux boundary conditions. Regarding (b) we show, that resolving the flow field, the refrigerated vehicle's walls and their conjugate heat transfer arrives at much closer accordance to measured data from the open door test.

With its remarkable scalability on parallel computer hardware, the LBM gained attention for turbulent flow simulations, especially in conjunction with LES in the last years [19]. The first LBM-LES model based on standard Smagorinsky eddy viscosity was proposed by Hou et al. [20]. Teixeira [21] further discussed incorporation methods for the k- $\epsilon$ and RNG turbulence models into the lattice Boltzmann algorithm. Dong and Sagaut [22] extended Hou's approach by to be inertial range-consistent and later Malaspinas and Sagaut [23] proposed consistent subgrid closures for the BGK Boltzmann equation.

Studies using Thermal Lattice Boltzmann Method (TLBM) have been carried out on the natural convection in square or cubic enclosures, but only few researchers used applications to show the possibilities in a turbulent regime. Khan et al. [24] used the lattice Boltzmann method (LBM) and compared it to a CFD-based large eddy simulation, studying the turbulent air flow and temperature field in a four-bed hospital room. At an urban scale, Obrecht et al. [25] carried out simulations of a small village and the velocity and temperature distributions between single houses. Tiftikci and Kocar [26] investigated heat distribution inside a 7-pin Indian Prototype Fast Breeder Reactor by LBM simulations, comparing their findings with experimental data. Yuan et al. [27] used GPU computations on 250 million grid points to examine the thermal comfort of indoor air flows. Most of these authors use the multiple relaxation time (MRT) collision operator for turbulent flows as the BGK collision operator is described as unstable in this flow regime.

In this work, we investigate the employability of the double distribution TLBM to the simulation of a refrigerated vehicle's insulation. For this purpose we examine the BGK-type collision and its extension of a Smagorinsky-type subgrid scale model on up to 2,000 CPU-Cores. For the first time, we show its proper stability and accuracy in the benchmark case natural convection in a square cavity for relaxation times as low as $\tau=0.5001$ with Ra numbers up to $10^{10}$.

This paper is organized in eight sub-sections. The first four present the governing equations, the turbulence model, applied boundary conditions and the conjugate heat flux method. The following section presents and discusses results of two benchmark cases and shows the model's application to cooling vehicle simulation. A conclusion is given in the final section. 


\section{Mathematical modeling and numerical method}

In order to simulate the incompressible air flow within the Boussinesq approximation we apply a double distribution BGK-LBM as described in [28]. Two different distribution functions $-f$ for momentum and $g$ for temperature - are solved.

\subsection{Lattice Boltzmann equations}

The Lattice Boltzmann Equation (LBE) including a force term $F_{i}(x, t)$ is given by

$$
f_{i}\left(x+c_{i} \Delta t, t+\Delta t\right)-f_{i}(x, t)=\Delta t\left(\Omega_{f, i}(x, t)+F_{i}(x, t)\right),
$$

where $f_{i}$ denotes the discrete probability function and $x$ denotes the space coordinate, $t$ the time coordinate, $i$ the discrete direction and $c_{i}$ the discrete velocity in direction $i$. The collision operator $\Omega_{i}(x, t)$ is given by the Bhatnagar-Gross-Krook (BGK) operator [28], which is also known as a Single Relaxation Time operator (SRT),

$$
\Omega_{f, i}(x, t)=-\frac{1}{\tau_{f}}\left(f_{i}(x, t)-f_{i}^{e q}(x, t)\right) .
$$

In this equation, $\tau_{f}$ represents the relaxation time and $f^{e q}$ the equilibrium distribution given by

$$
f_{i}^{e q}(\rho, u)=w_{i} \rho\left(1+\frac{u \cdot c_{i}}{c_{s}^{2}}+\frac{\left(u \cdot c_{i}\right)^{2}}{2 c_{s}^{4}}-\frac{u \cdot u}{2 c_{s}^{2}}\right) .
$$

With $w_{i}$ denoting the weights of the discrete directions and $c_{s}$ denoting the speed of sound. The macroscopic density $\rho$ and velocity $u$ are obtained from the distribution function's moments

$$
\rho(x, t)=\sum_{i} f_{i}(x, t) \text { and } u=\frac{1}{\rho} \sum_{i} c_{i} f_{i}(x, t)
$$

Through the Chapman-Enskog analysis, as described e.g. by Krüger [28], a relationship between viscosity and relaxation time is obtained as

$$
\tau_{f}=\frac{v}{c_{s}^{2}}+\frac{1}{2}
$$

Since in this paper not only the previously described LBE is used for the computation of the isothermal and incompressible fluid properties pressure and velocity, but also for different temperatures, the convection-diffusion-equation is solved as well. Analogous to the LBM for fluid properties, the discrete representation of the convection-diffusion equation in the means of LBM is given as (see e.g. [29])

$$
g_{i}\left(x+c_{i} \Delta t, t+\Delta t\right)-g_{i}(x, t)=\Delta t \Omega_{g, i}(x, t),
$$

Eq. (7) shows the collision operator for the Convection-Diffusion Equation (CDE), using the relaxation time $\tau_{g}$ for thermal consideration.

$$
\Omega_{g, i}(x, t)=-\frac{1}{\tau_{g}}\left(g_{i}(x, t)-g_{i}^{e q}(x, t)\right)
$$

The equilibrium distribution is given by

$$
g_{i}^{e q}(x, t)=\frac{\omega_{i} T}{4}\left(1+2 \frac{u \cdot c_{i}}{c_{s}^{2}}\right)
$$

where the macroscopic velocities are obtained from (4) and macroscopic temperature $T$ and heat flux $q$ are given by the zeroth and first moment, respectively:

$$
T(x, t)=\sum_{i} g_{i}(x, t) \text { and } q(x, t)=\frac{\tau_{g}-\frac{1}{2}}{\tau_{g}} \sum_{i} c_{i} g_{i}(x, t)
$$

A Chapman-Enskog analysis according to Mohamad [29] again leads to a relation between the relaxation time of the temperature distribution and the fluid's thermal conductivity $\kappa$ given by

$$
\tau_{g}=\frac{\kappa}{c_{s}^{2}}+\frac{1}{2}
$$

Discrete velocity directions are used in the LBM. These directions are usually denoted by DdQq, d denoting the velocity space's dimensions and q the discrete directions. Fig. 1 shows the schematic representation of the D3Q19 and D3Q7 discrete velocity combinations used for the purpose of this paper. Depending on the direction of motion, predefined weighting factors 


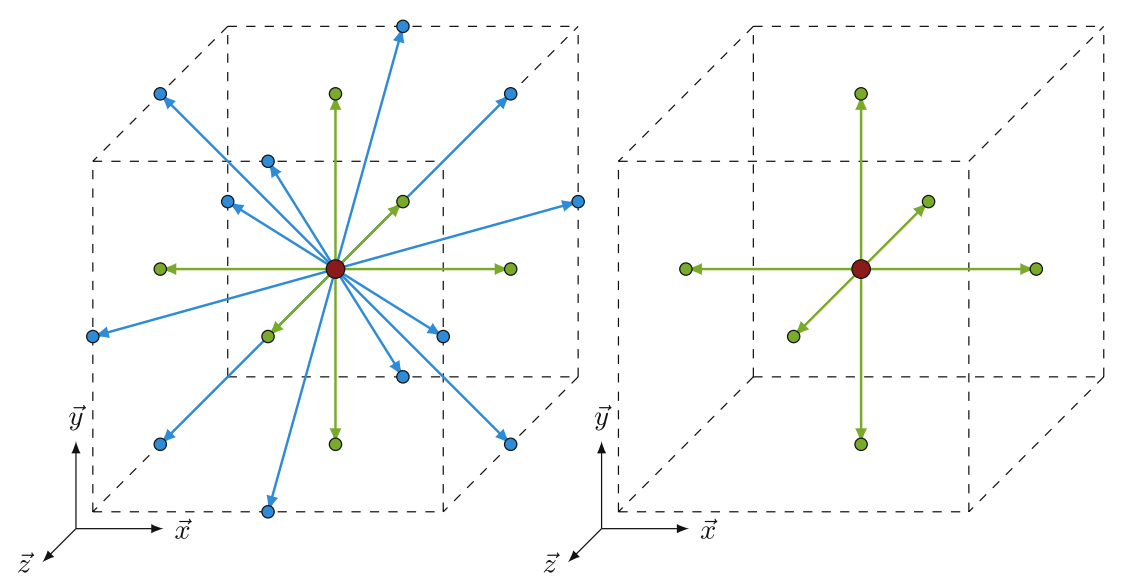

Fig. 1. Schematic representation of speed directions according to D3Q19 and D3Q7.

$w_{i}$ - distinguished by different colors in Fig. 1 - is expressed in (11) for D3Q19 and in (12) for D3Q7. Note that the speed of sound in lattice units is $c_{s}=\sqrt{\frac{1}{3}}$ in the D3Q19 lattice and $c_{s}=\sqrt{\frac{1}{4}}$ in the D3Q7 lattice.

D3Q19: $\quad w_{i}= \begin{cases}\frac{12}{36}, & \text { red direction } \\ \frac{2}{36}, & \text { green direction } \\ \frac{1}{36}, & \text { blue direction }\end{cases}$

D3Q7: $w_{i}= \begin{cases}\frac{2}{8}, & \text { red direction } \\ \frac{1}{8}, & \text { green direction }\end{cases}$

To couple the two fields, the force term according to (1) is used. The Boussinesq buoyancy force is given by

$$
F(x, t)=-\rho_{0} \beta g\left(T(x, t)-T_{0}\right),
$$

where $\beta$ denotes the expansion coefficient of the fluid and $g$ the gravitational acceleration. We use the forcing method described by Guo et al. [30], where from we obtain the lattice forcing term $F_{i}$ from $F$.

Our algorithm combines these two discretized equations for velocity and temperature distributions with coupling via the Boussinesq approximation. This essentially combines a collision step and a streaming step. We

- conduct the stream and collide step in the momentum lattice $f$ with the last time step's force term,

- then collide and stream in the temperature lattice $g$ with the last time step's velocity values.

- Subsequently, we execute the coupling process by updating the momentum lattice's forcing term and

- communicating the macroscopic velocity to the temperature lattice.

So, values from the last time step are used, instead of communicating newly calculated values between the two lattices. Only locally available cell data is accessed during the collision step. This proves to be computationally more efficient.

\subsection{Smagorinsky subgrid scale model}

To efficiently simulate the flow field in the turbulent regime and the flow field's characteristics, we use the Smagorinsky subgrid-scale model [20]. In this method the effective viscosity $v_{\text {eff }}$ is treated as the sum of molecular $v_{0}$ and eddy viscosity $v_{t}$ as

$$
v_{\mathrm{eff}}=v_{0}+v_{t}=v_{0}+\left(C_{S} \Delta\right)^{2} \sqrt{2 \sum_{\alpha, \beta} S_{\alpha \beta} S_{\alpha \beta}},
$$


where the strain rate $S_{\alpha \beta}$ is locally computed using the non-equilibrium stress tensor $\Pi_{\alpha, \beta}^{(\text {neq })}$ by

$$
S_{\alpha \beta}=-\frac{1}{2 \rho \tau^{*} c_{s}^{2}} \Pi_{\alpha, \beta}^{(n e q)}=-\frac{1}{2 \rho \tau^{*} c_{s}^{2}} \sum_{q} e_{i, \alpha} e_{i, \beta}\left(f_{i}-f_{i}^{(e q)}\right) .
$$

With $\tau^{*}=\frac{v_{\text {eff }}}{c_{s}^{2}}+\frac{1}{2}$ is denoting the modified relaxation time as a function of $v_{\text {eff }}$.

Analogous to the calculation of $v_{\text {eff }}$, the effective thermal diffusivity is calculated by

$$
\alpha_{\text {eff }}=\alpha_{0}+\alpha_{t}=\alpha_{0}+\frac{\nu_{t}}{\operatorname{Pr}_{t}},
$$

where the turbulent thermal diffusivity $\alpha_{t}$ is calculated by the turbulent Prandtl number

$$
\operatorname{Pr}_{t}=\frac{v_{t}}{\alpha_{t}} \text {. }
$$

Although this approach is broadly used in simulations and described in the literature [31], there is up to now no consent on how to chose $\operatorname{Pr}_{t}$ correctly, as values vary from 0.3 in experiments to 0.86 derived theoretically up to 1.0 and even larger in some regions close to the wall in DNS simulations [32-34]. We state the applicability of this approach and accuracy in combination with our SRT-LBM and with a fixed $\operatorname{Pr}_{t}=0.86$ in Section 3.1.2 by comparing results from the well known benchmark case for natural convection in a square cavity against values from the literature.

\subsection{Boundary conditions}

For pressure and velocity boundary conditions, we use the regularized boundary approach as described by Latt [35]. The Dirichlet-type temperature boundary condition is implemented as described in [28] and the Neumann-type boundary for temperature is used as recommended by Junk and Yang [36]. Simple bounce back [37] is used for no-slip and adiabatic boundaries.

\subsection{Conjugate heat transfer}

To simulate heat transfer between a solid material and a fluid streaming around it, we use the half lattice division scheme described by Wang [38]. The diffusion equation for the solid's temperature distribution and the convection-diffusionequation for the fluid's temperature distribution are solved on a single mesh. Different temperature conductivities are taken into account through space variant relaxation times $\tau_{g, \text { solid }}$ and $\tau_{\text {g,fluid }}$. This approach is valid in a strictly sense only for steady state problems and $\rho_{\text {solid }} c_{p \text {,solid }}=\rho_{\text {fluid }} c_{p, \text { fluid }}$, where $\rho$ denotes the density and $c_{p}$ denotes the specific heat capacity. By choosing the lattice units as $\rho_{\text {fluid }}^{*}=1$ and $\rho_{\text {solid }}^{*}=\rho_{\text {fluid }}^{*} \frac{c_{p, \text { fluid }}}{c_{p, \text { solid }}}$ the latter condition is fulfilled.

\section{Results and discussion}

In this section we show results for two benchmark cases, where we compare results from our present model to analytic solution and literature results, respectively. Subsequently, the model is applied to the simulation of a refrigerated vehicle. All simulations are conducted in the open source software package OpenLB (openlb.net) [39]. The LBM for the flow field including the Smagorinsky subgrid model and the LBM for the temperature field are implemented and extend by the Smagorinsky subgrid model for the temperature. Due to its generic approach based on C++ templates, OpenLB has been used for several applications in math, engineering and medicine, see for example $[40,41,18,42,43]$.

\subsection{Benchmarks}

\subsubsection{Porous plate problem}

To verify the present model's grid convergence for different lattice relaxation times $\tau_{f}$ and $\tau_{g}$, we conduct simulations of the porous plate problem [44,45], which - to the knowledge of the authors -has not been done before with a 3D LBM. The porous plate problem describes a channel flow, where the upper cool plate moves with a constant velocity and through the bottom warm plate a constant normal flow is injected and withdrawn at the same rate at the upper plate. At the left and right hand side as well as at the front and the back of the domain, periodic boundary conditions are applied. Constant velocity and temperature boundary conditions are applied to the top and bottom plates according to Fig. 2 .

An analytic solution for this steady state problem is given for the velocity and temperature distributions by [44]:

$$
\begin{aligned}
& u_{x}(y)=u_{x, 0}\left(\frac{e^{R e \cdot y / L}-1}{e^{R e}-1}\right) \\
& T(y)=T_{0}+\Delta T=\left(\frac{e^{P r \cdot R e \cdot y / L}-1}{e^{P r \cdot R e}-1}\right)
\end{aligned}
$$




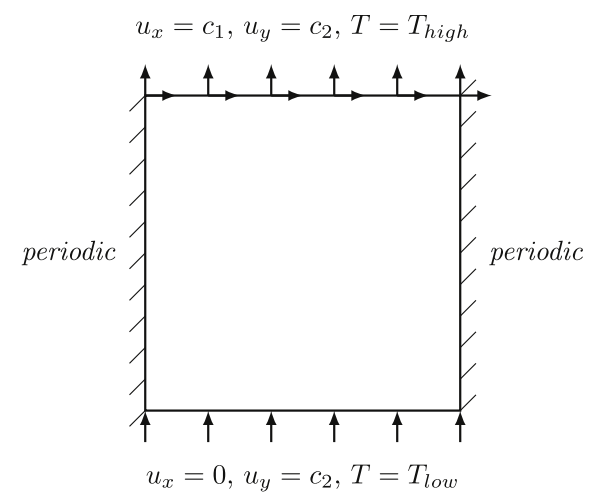

Fig. 2. Schematic representation of the simulation setup of the porous plate problem including its boundary conditions.

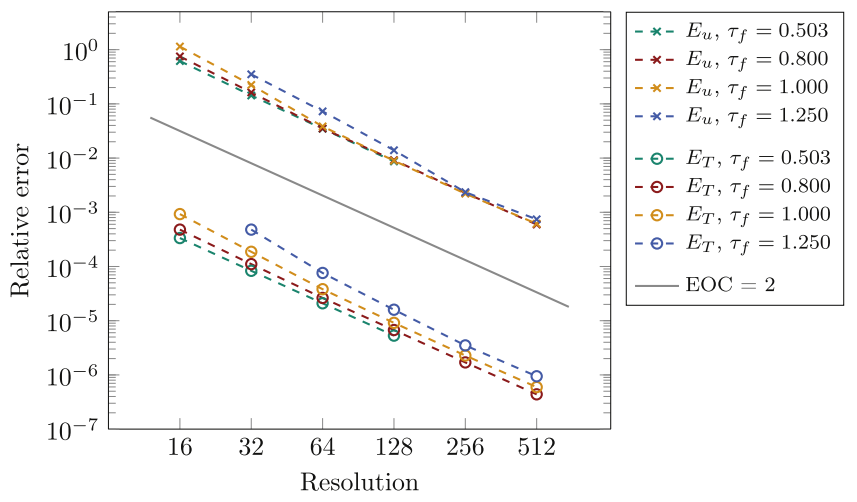

Fig. 3. Relative error for velocity $E_{u}$ and temperature $E_{T}$ plotted logarithmically over the resolution: Negative slope of about two shows the method's second order accuracy.

where $u_{x, 0}$ denotes the upper plate's velocity, $R e=\frac{u_{y, 0} L}{v}$ the Reynolds number depending on the injected velocity $u_{y, 0}$, the fluid's viscosity $v$ and the channel length $L$ and $P r=\frac{v}{\alpha}$ the Prandtl number. The temperature difference between the hot and cold plate is given by $\Delta T=T_{h}-T_{c}$. For the grid independence study, we choose $\operatorname{Re}=5, \operatorname{Pr}=0.71$ and Rayleigh number $R a=\frac{g \beta}{v \alpha} \Delta T L^{3}=100$. The relaxation time is varied as $\tau=1.2,1.0,0.8$ and 0.503 and resolution is varied as the number of grid cells in $x$ and $y$ direction $N=16,32,64,128$ and 256 .

Relative global errors in temperature and velocity fields are shown logarithmically in Fig. 3 with the relative global error defined by

$$
E_{\phi}=\frac{\sqrt{\Delta x^{3} \sum_{x}\left|\phi(x)-\phi_{a}(x)\right|^{2}}}{\sqrt{\Delta x^{3} \sum\left|\phi_{a}(x)\right|^{2}}},
$$

where summation goes over the entire flow domain, $\phi$ denotes the quantity of interest, either the velocity or the temperature, and $\phi_{a}$ is the analytic solution given by (18) and (19).

Fig. 3 shows clearly that this three dimensional model and its present implementation is of second order in space for both velocity and temperature. It is shown, that the double distribution BGK scheme is accurate for several values of $\tau_{f}$ and is stable for values as low as $\tau_{f}=0.503$.

\subsubsection{Natural convection in a square cavity}

To obtain evidence for the turbulence modeling approach and implementation the principle of static buoyancy is used within a square cavity, which has been numerically studied by many authors [46-48]. In this case, air in a three-dimensional cavity with different, but constant temperatures on the vertical walls is simulated. The horizontal walls of the geometry are considered adiabatic as shown in Fig. 4. In $\mathrm{z}$ direction the domain is three grid points deep and considered periodic.

Since the walls of the cavity are considered to be fluid-impermeable regions, the illustrated edges obtain the no-slip condition. The initial velocity in the entire cavity is set to $u=0$. The parameters of air were obtained from Hortmann [49] and are shown in Table 1. 


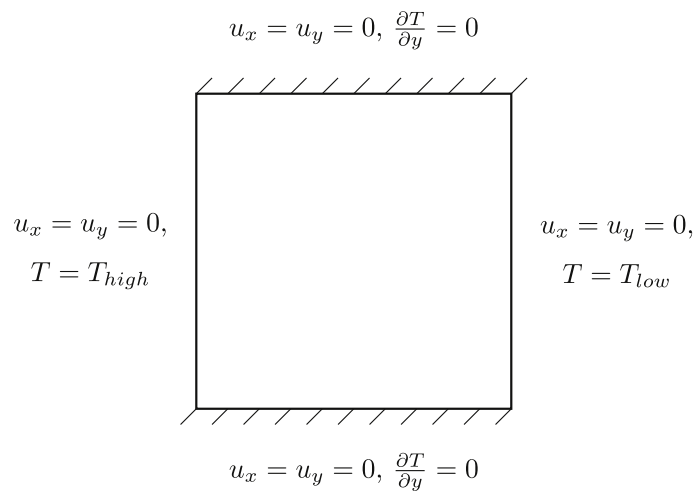

Fig. 4. Schematic representation of the simulation domain for the natural convection in a square cavity including its boundary conditions.

Table 1

Properties of air from Hortmann [49] used for the validation of the natural convection in a cavity.

\begin{tabular}{ll}
\hline Properties of air & \\
\hline$\lambda$ & $2.5684 \cdot 10^{-2} \mathrm{~W} /(\mathrm{m} \mathrm{K})$ \\
$\nu$ & $1.5126 \cdot 10^{-5} \mathrm{~m}^{2} / \mathrm{s}$ \\
$\rho$ & $1.19 \mathrm{~kg} / \mathrm{m}^{3}$ \\
$\beta$ & $3.41 \cdot 10^{-3} 1 / \mathrm{K}$ \\
$c_{p}$ & $1.01309 \cdot 10^{3} \mathrm{~J} /(\mathrm{kg} \mathrm{K})$ \\
\hline
\end{tabular}

Table 2

Obtained values by simulating the natural convection in a square cavity geometry for different Rayleigh numbers and the results of De Vahl Davis [47].

\begin{tabular}{|c|c|c|c|c|c|}
\hline $\begin{array}{l}\text { Ra } \\
\text { Grid used }\end{array}$ & & $\begin{array}{l}10^{3} \\
(64 \times 64 \times 3)\end{array}$ & $\begin{array}{l}10^{4} \\
(128 \times 128 \times 3)\end{array}$ & $\begin{array}{l}10^{5} \\
(256 \times 256 \times 3)\end{array}$ & $\begin{array}{l}10^{6} \\
(512 \times 512 \times 3)\end{array}$ \\
\hline$y_{\max }$ & $\begin{array}{l}{[47]} \\
\text { Present }\end{array}$ & $\begin{array}{l}0.813 \\
0.828\end{array}$ & $\begin{array}{l}0.823 \\
0.828\end{array}$ & $\begin{array}{l}0.855 \\
0.859\end{array}$ & $\begin{array}{l}0.850 \\
0.852\end{array}$ \\
\hline$u_{x, \max }$ & $\begin{array}{l}{[47]} \\
\text { Present }\end{array}$ & $\begin{array}{l}3.649 \\
3.500\end{array}$ & $\begin{array}{l}16.178 \\
16.210\end{array}$ & $\begin{array}{l}34.730 \\
34.792\end{array}$ & $\begin{array}{l}64.630 \\
64.957\end{array}$ \\
\hline$x_{\max }$ & $\begin{array}{l}{[47]} \\
\text { Present }\end{array}$ & $\begin{array}{l}0.178 \\
0.172\end{array}$ & $\begin{array}{l}0.119 \\
0.125\end{array}$ & $\begin{array}{l}0.066 \\
0.063\end{array}$ & $\begin{array}{l}0.038 \\
0.039\end{array}$ \\
\hline$u_{y, \max }$ & $\begin{array}{l}{[47]} \\
\text { Present }\end{array}$ & $\begin{array}{l}3.697 \\
3.760\end{array}$ & $\begin{array}{l}19.617 \\
19.438\end{array}$ & $\begin{array}{l}68.590 \\
68.413\end{array}$ & $\begin{array}{l}219.360 \\
219.537\end{array}$ \\
\hline$\overline{\mathrm{Nu}}_{0}$ & $\begin{array}{l}{[47]} \\
\text { Present }\end{array}$ & $\begin{array}{l}1.117 \\
1.116\end{array}$ & $\begin{array}{l}2.238 \\
2.216\end{array}$ & $\begin{array}{l}4.509 \\
4.503\end{array}$ & $\begin{array}{l}8.817 \\
8.772\end{array}$ \\
\hline
\end{tabular}

The natural convection developing within the cavity is analyzed for different Rayleigh numbers of $R a=10^{3}, 10^{4}, 10^{5}$ and $10^{6}$ for the laminar regime and $R a=10^{7}, 10^{8}, 10^{9}$ and $10^{10}$ for the turbulent regime by means of the following quantities:

- the maximum vertical velocity $u_{x, \max }$ on the horizontal mid-plane of the cavity and its position $y_{\max }$,

- the maximum horizontal velocity $u_{y, \max }$ on the vertical mid-plane of the cavity and its position $x_{\max }$

- the average Nusselt number $\bar{N} u$ on the boundary of the cavity at $x=0$.

For the laminar cases up to $R a=10^{6}$ we chose the lattice Mach number as $M a=\frac{u_{\max }}{c_{s}}=0.1$, where $u_{\max }$ is the expected maximum velocity from the literature results and we chose the respective resolutions as shown in Table 2. Convergence is assumed, when the relative standard deviation of five following Ra numbers calculated each 1000 time steps is below $\epsilon=10^{-5}$. Table 2 shows the results of the present scheme as well as the relative errors against the values of De Vahl Davis [47], which have already been considered by various authors as a comparative solution using different numerical methods.

To visualize the flow inside the cavity and the resulting differences for the simulated Rayleigh numbers, streamlines and isotherms are shown in Figs. 5 and 6. The vortex at the middle, which develops with a Rayleigh number of $R a=10^{3}$, can be seen clearly and is based on buoyancy of heated and sinking of cold air. On account of the temperature differences of the two walls, a Rayleigh number of $R a=10^{3}$ results in the displacement of the mean vertical isotherms, where the temperature gradients are approaching further into the direction of the vertical walls. As the Rayleigh number increases, the vortex at the middle changes into an ellipse shape and from a Rayleigh number of $R a=10^{5}$ finally divides into two partial vortices, which drift horizontally in the direction of the adiabatic walls. 

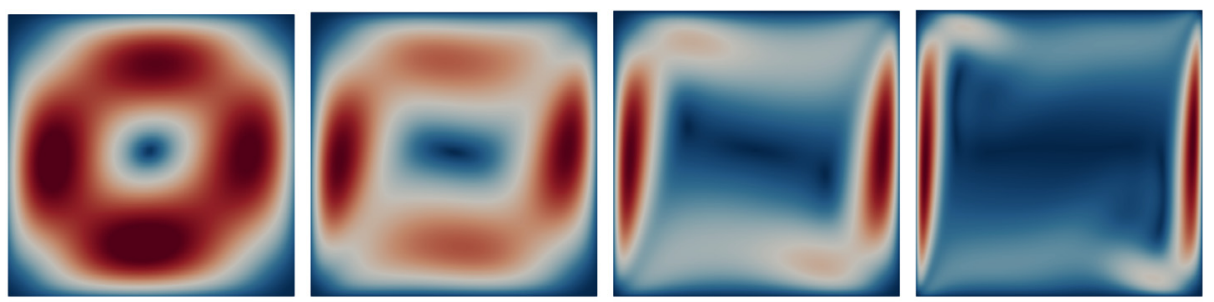

$0.0 \quad 0.2 \quad \begin{array}{llllll}0.4 & 0.6 & 0.8 & 1.0\end{array}$

Fig. 5. Converged velocity distributions for the natural convection in a square cavity with Rayleigh numbers Ra $=10^{3}, 10^{4}, 10^{5}$ and $10^{6}$ (left to right) colored analogous to the dimensionless velocity magnitude: red indicates high, blue indicates low.
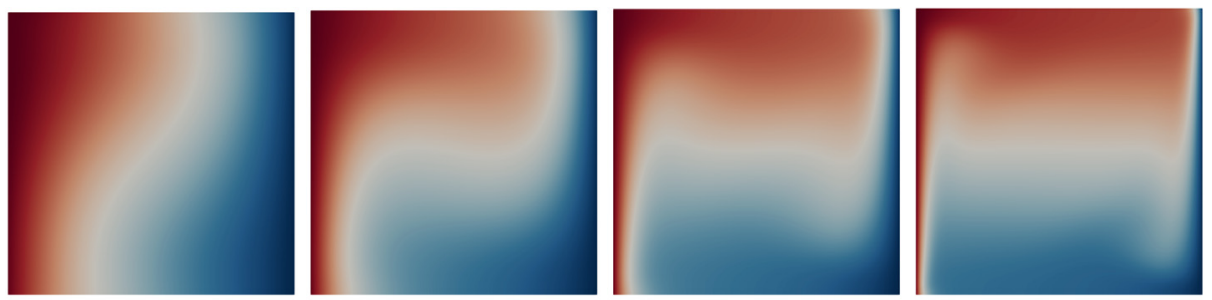

$0.0 \quad$ reduced temperatur

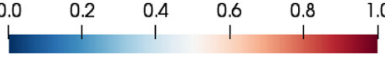

Fig. 6. Converged temperature distributions for the natural convection in a square cavity with Rayleigh numbers Ra $=10^{3}, 10^{4}, 10^{5}$ and $10^{6}$ (left to right) colored analogous to the dimensionless temperature: red indicates high, blue indicates low.

Beginning with a Rayleigh number of $R a=10^{5}$, the isotherms are found to be approximately horizontal to the cavity geometry, limiting fluid movement in the vertical direction. The main heat exchange is now effected only by convection in the region of the edges, with high temperature gradients and subsequently high acceleration in the fluid. At a Rayleigh number of $R a=10^{6}$, the displacement of the partial vortices occurs in the corners of the cavity, whereupon a third vortex is formed in the middle, which also rotates clockwise. The velocity and temperature fields compare very well with the illustrations in the literature by De Vahl Davis, Guo or Peng $[47,44,45]$.

For the turbulent cases from $R a=10^{7}$ to $10^{10}$ we use the Double Smagorinsky Subgrid Scaling Method (DSSSM) as described in Section 2.2. Again, we choose the lattice Mach number to be $M a=0.1$ for all cases and a convergence residuum of $\epsilon=10^{-3}$. To further assure a reasonable fine mesh for the large and medium large eddies to be resolved, we introduce a dimensionless wall spacing $y^{+}[50]$ with

$$
y^{+}=\frac{\Delta x u_{\tau}}{v}
$$

where

$$
u_{\tau}=u_{\max } \sqrt{\frac{0.026}{2}\left(\frac{v}{u_{\text {max }} d_{\text {wall }}}\right)}
$$

denotes the friction velocity. Here, $d_{\text {wall }}$ is the distance from the position of the maximum velocity to the wall. Table 3 compares the results of the present model against values from $[48,51,46]$ for $y^{+}=2$.

As turbulence is a chaotic state, the calculated values are time dependent and relative deviation is not necessarily a miscalculation itself. Within this constraint, the present model obtains values very close to those from comparative studies, especially for the relatively small resolutions used here. Maximum velocities' deviations are occurring close to the cavities' walls. Implementing a turbulent wall boundary condition could surely achieve closer results. Such a boundary condition for the turbulent temperature boundary layer is not yet incorporated in the LBM and is subject to the author's subsequent publication. The instantaneous velocity and temperature fields in Figs. 7 and 8 compare very well against the illustrations in the literature by Dixit [46], although he used time averaged values for his visualizations.

\subsection{Application to refrigerated vehicles}

The validation of a realistic mapping of flow and the temperature distributions in the interior of a refrigerated transport structure is of crucial importance for simulations of various wall structures and loading cases. Hence, high priority is 
Table 3

Simulated values of turbulent cases of natural convection in a square cavity geometry for different Rayleigh numbers and the results of [48,51,46].

\begin{tabular}{|c|c|c|c|c|c|}
\hline $\begin{array}{l}\text { Ra } \\
\text { Grid used }\end{array}$ & & $\begin{array}{l}10^{7} \\
(47 \times 47 \times 3)\end{array}$ & $\begin{array}{l}10^{8} \\
(139 \times 139 \times 3)\end{array}$ & $\begin{array}{l}10^{9} \\
(392 \times 392 \times 3)\end{array}$ & $\begin{array}{l}10^{10} \\
(1138 \times 1138 \times 3)\end{array}$ \\
\hline$y_{\max }$ & $\begin{array}{l}{[48]} \\
{[51]} \\
{[46]} \\
\text { Present }\end{array}$ & $\begin{array}{l}- \\
0.879 \\
0.851 \\
0.905\end{array}$ & $\begin{array}{l}0.941 \\
0.928 \\
0.937 \\
0.945\end{array}$ & $\begin{array}{l}- \\
- \\
0.966 \\
0.950\end{array}$ & $\begin{array}{l}0.9625 \\
- \\
0.9402 \\
0.907\end{array}$ \\
\hline$u_{x, \max }$ & $\begin{array}{l}{[48]} \\
{[51]} \\
{[46]} \\
\text { Present }\end{array}$ & $\begin{array}{l}- \\
148.58 \\
164.236 \\
130.221\end{array}$ & $\begin{array}{l}514.3 \\
321.9 \\
389.877 \\
280.674\end{array}$ & $\begin{array}{l}- \\
- \\
503.24 \\
2277.140\end{array}$ & $\begin{array}{l}2323 \\
- \\
2323 \\
2967.5\end{array}$ \\
\hline$x_{\max }$ & $\begin{array}{l}{[48]} \\
{[51]} \\
{[46]} \\
\text { Present }\end{array}$ & $\begin{array}{l}- \\
0.021 \\
0.020 \\
0.042\end{array}$ & $\begin{array}{l}0.0135 \\
0.012 \\
0.0112 \\
0.014\end{array}$ & $\begin{array}{l}- \\
- \\
0.0064 \\
0.008\end{array}$ & $\begin{array}{l}0.0055 \\
- \\
0.4907 \\
0.004\end{array}$ \\
\hline$u_{y, \max }$ & $\begin{array}{l}{[48]} \\
{[51]} \\
{[46]} \\
\text { Present }\end{array}$ & $\begin{array}{l}- \\
699.236 \\
701.922 \\
467.976\end{array}$ & $\begin{array}{l}1812 \\
2222.39 \\
2241.374 \\
1860.270\end{array}$ & $\begin{array}{l}- \\
- \\
6820.07 \\
6124.420\end{array}$ & $\begin{array}{l}21463 \\
- \\
21463 \\
20533\end{array}$ \\
\hline$\overline{\mathrm{Nu}}_{0}$ & $\begin{array}{l}{[48]} \\
{[51]} \\
{[46]} \\
\text { Present }\end{array}$ & $\begin{array}{l}- \\
16.523 \\
16.79 \\
16.987\end{array}$ & $\begin{array}{l}32.045 \\
30.225 \\
30.506 \\
32.076\end{array}$ & $\begin{array}{l}- \\
- \\
57.350 \\
52.260\end{array}$ & $\begin{array}{l}156.85 \\
- \\
103.663 \\
102.034\end{array}$ \\
\hline
\end{tabular}
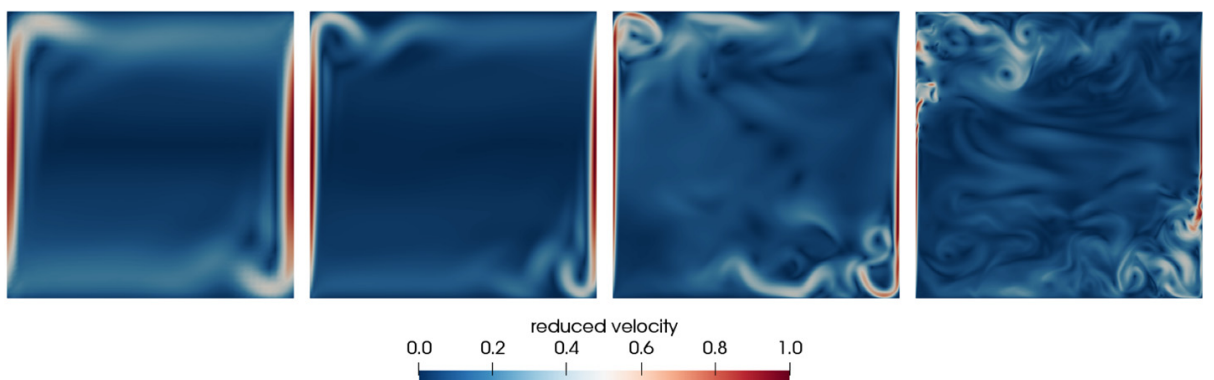

Fig. 7. Instantaneous velocity distributions for the natural convection in a square cavity with Rayleigh numbers Ra $=10^{7}, 10^{8}, 10^{9}$ and $10^{10}($ left to right) colored analogous to the dimensionless velocity magnitude: red indicates high, blue indicates low.
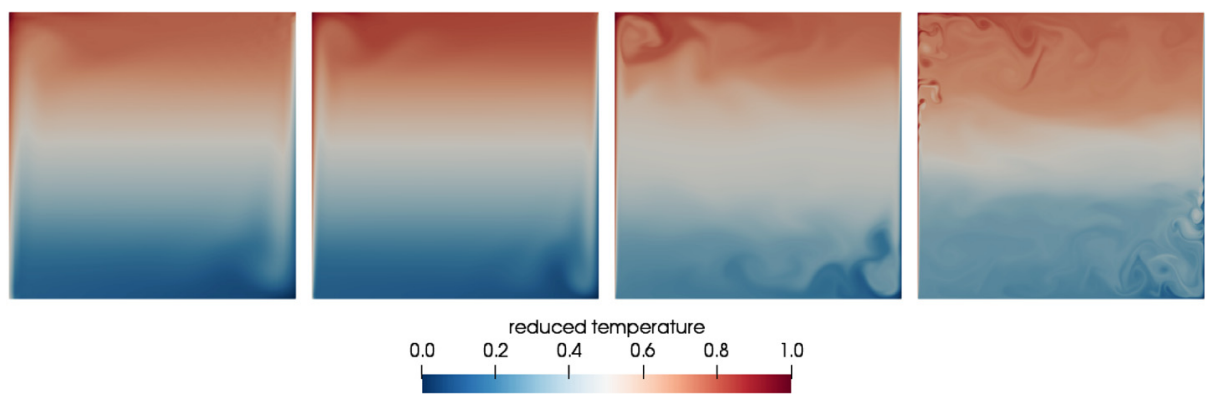

Fig. 8. Instantaneous temperature distributions for the natural convection in a square cavity with Rayleigh numbers $\mathrm{Ra}=10^{7}, 10^{8}, 10^{9}$ and $10^{10}($ left to right) colored analogous to the dimensionless temperature: red indicates high, blue indicates low.

attributed to the validation of the cooling construction and an experimental measurement is carried out for a verification of the results of the simulation. Section 3.2.1 shows the design of the geometry of the structure for measurements of air speed and temperature values, as well as the transferred and implemented geometry within which the simulation is to take place. The comparison between experimental data and the corresponding simulation of the speed and temperature fields is given in Section 3.2.2. 


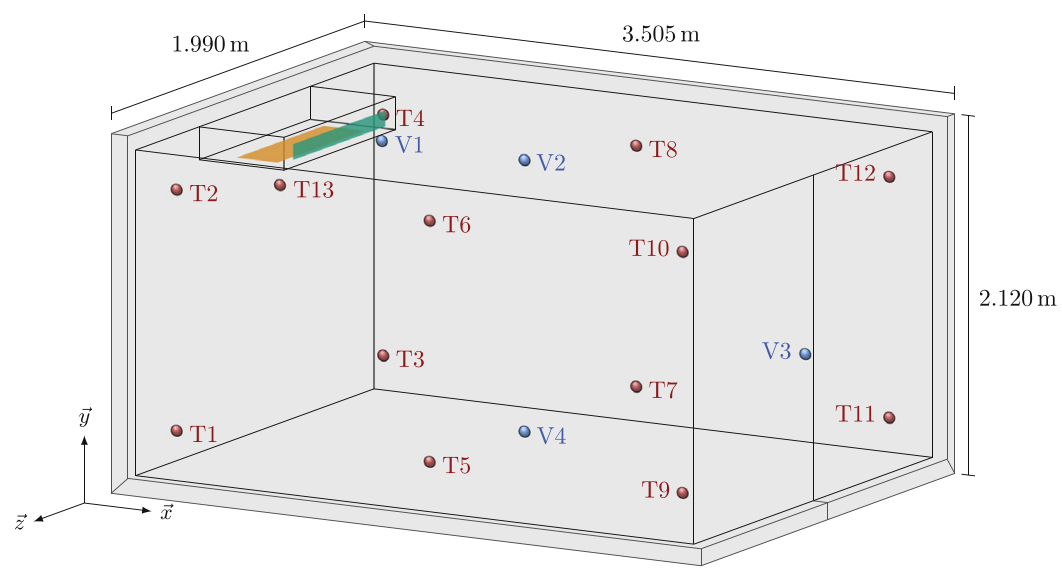

Fig. 9. Schematic representation of the cooling system and the built-in air conditioning system with registered speed (blue) and temperature measuring points (red), as well as their numbering. The air conditioning's outlet and suction side are shown in green and orange, respectively. (For interpretation of the references to color in this figure legend, the reader is referred to the web version of this article.)

Table 4

Used properties for air from the literature according to VDI-Wärmeatlas, as well as the data of the insulation, geometry and required numerical parameters.

\begin{tabular}{llll}
\hline \multicolumn{2}{l}{ Properties of air } & \multicolumn{2}{l}{ Properties of insulation } \\
\hline$\lambda$ & $2.262 \cdot 10^{-2} \mathrm{~W} /(\mathrm{m} \mathrm{K})$ & $\lambda$ & $2.3 \cdot 10^{-2} \mathrm{~W} /(\mathrm{m} \mathrm{K})$ \\
$\rho$ & $1.3782 \mathrm{~kg} / \mathrm{m}^{3}$ & $\rho$ & $3.950 \cdot 10^{1} \mathrm{~kg} / \mathrm{m}^{3}$ \\
$c_{p}$ & $1.0068 \cdot 10^{3} \mathrm{~J} /(\mathrm{kg} \mathrm{K})$ & $c_{p}$ & $1.400 \cdot 10^{3} \mathrm{~J} \mathrm{~K} / \mathrm{kg}$ \\
$\beta$ & $3.974 \cdot 10^{-3} 1 / \mathrm{K}$ & & \\
$\nu$ & $1.1766 \cdot 10^{-5} \mathrm{~m}^{2} / \mathrm{s}$ & & \\
\hline
\end{tabular}

\subsubsection{Simulation and measurement set-up}

The geometry models a CoolerBox 2.0 TK 3500 HS refrigerated transporter of the company Kress Fahrzeug GmbH with a two-winged door. This transporter uses a Carrier Xarios 500T cooling unit, which can be used for both heating and cooling purposes. The energy supply of the transport cooling system can be provided either by means of the diesel engine of the vehicle during journeys, or by $400 \mathrm{~V}$ three-phase current during longer periods of rest. The manufacturer's specifications for the cooling system state a full-load volume flow of $\dot{V}=990 \mathrm{~m}^{3} / \mathrm{h}$ and a heating and cooling capacity of $\dot{Q}=950 \mathrm{~W}$. This full-load volume flow results in a maximum inlet velocity of $u_{\text {inlet }}=5.587 \mathrm{~m} / \mathrm{s}$ and a corresponding Reynolds number of $R e=\frac{u_{\text {inlet }} d_{h}}{v}=52959$ with the hydraulic diameter $d_{h}=0.1115 \mathrm{~m}$. Dimensions of the overall structure and the air conditioner with air inflow and outflow are given in Fig. 9.

To simulate in this geometry, we choose a resolution of 253.8 millions cells and a maximum lattice velocity $u^{*}=0.1$. We use OpenLB's OpenMPI-based domain decomposition method [17] to efficiently parallelize to a total number of $2000 \mathrm{CPU}$ cores achieving approximately 3200 mega lattice updates per second (MLUPs) for the present coupled model.

To determine the temporal temperature distribution, 13 temperature measuring devices were installed in the cooler construction according to Fig. 9 plus one temperature measuring device underneath the cooling transporter to determine the ambient temperature. The velocity distribution of the air flow was recorded at four characteristic measuring points using a hand held anemometer with the vehicle's built-in air conditioner working at full power. In the simulation, these velocity and temperature measuring points were realized, analogously to Fig. 9, through spheres with a diameter of $d_{m p}=0.05 \mathrm{~m}$, within which the simulated quantities were spatially averaged.

All parameters used for the description of flowing air as well as insulation used are listed in Table 4. It should be noted that the insulation is a three-layer structure consisting of two layers of glass-fiber-reinforced plastic sheets and a polyurethane hard foam layer with glass fiber admixture. The corresponding mean values of the simulated wall structure are shown in Table 4, as well.

Since only parameters relating to the cooling capacity and the volume flows at full load can readily be taken from the parameters of the air-conditioning system, a door test, whose experimental sequence is explained in more detail in the following section, is used as a validation case for the cooling construction.

\subsubsection{Comparison with open door test measurements}

In a door test, the rear door of the cooling compartment is opened for two minutes in order to effect an air exchange with the surroundings, following the closing of the door and the start of the air conditioning system. This is a frequent 


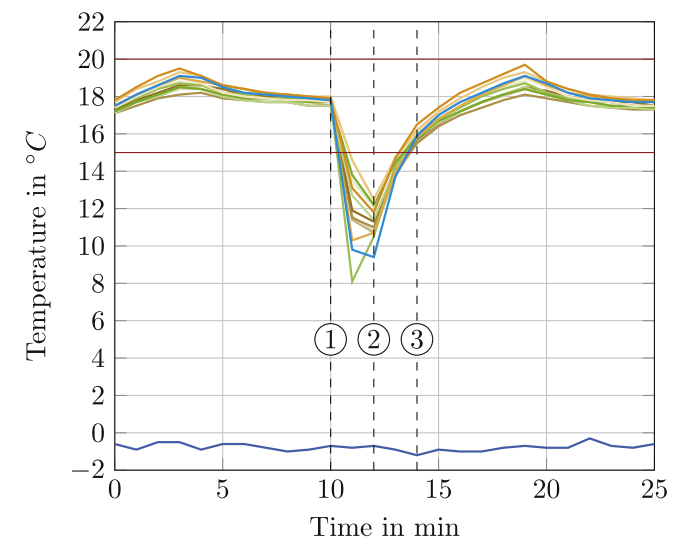

Fig. 10. Measurements of the refrigerated vehicle's temperatures during the heating operation with winter outside conditions. The door test with its individual phases and 13 temperature measuring points is shown. Higher and lower acceptance limits are displayed in red and the outside temperature is displayed in blue. (For interpretation of the references to color in this figure legend, the reader is referred to the web version of this article.)

application when delivering refrigerated goods or when loading and unloading a refrigerated transporter. Fig. 10 shows the temperature time measurements of the aforementioned thermocouples during a door test with the opening of the door at position 1, the closing of the door and the start of the air conditioning system at position 2 . Since the air conditioner determines a temperature below the chosen acceptance limit by means of a sensor, it starts the heating of the indoor space under full power. After $2 \mathrm{~min}$, at position 3, a temperature above the acceptance limit is reached and the air conditioning changes back to the cyclical mode.

The described sequence starting at position 2 for a time of one minute is simulated using the previously presented geometry and is used as a validation case. For this purpose, a polynomial approach profile to the maximum speed and a plugflow profile in the outlet, due to an upstream lattice in the real device, is implemented. The heating output is coupled into the system via an energy balance, whereby the volumetric flow into the device, its density and temperature are determined from the moments (4) and (9), and the new outlet temperature is calculated from these values with the values of the outlet volume flow, the density and the predetermined heating output. The specific heat capacity of air is assumed to be constant due to the low temperature dependence in the required range.

After one simulated minute, the results of the simulation are output from the individual implemented measuring spheres for speed and temperature and compared with the results of the experimental measurements. Fig. 11 shows streamline representations of the flow induced by the air conditioner (AC). The air streams out of the AC parallel to the ceiling. After hitting the back wall it is spread along the wall and directed downwards. From the vehicle's floor it is sucked into the AC again. Fig. 12 shows the velocity and the temperature fields of the simulated refrigerated vehicle.

The listed results for the individual measuring regions of the experimental measurements, the validation simulation and their absolute errors are given in Table 5 . With absolute errors of below $0.4 \mathrm{~m} / \mathrm{s}$ for the velocities and below $1 \mathrm{~K}$ for the temperatures these are very good agreement with our measurements. Other simulations (e.g. $[10,14,15])$ have found differences up to $50 \%$ for the velocities and between $3 \mathrm{~K}$ and $4 \mathrm{~K}$ for the temperatures in very similar geometries and measurement setups. This shows the advantage of the used method: By resolving a larger part of the turbulent energy spectrum compared to $\mathrm{k}-\epsilon$ turbulent models and by spatially resolving the walls heat flux instead of modeling it as constant heat flux boundary conditions, better agreement between measurements and simulation data is achieved.

Although, considering the high computation time and hardware requirements for following simulations, incorporating a turbulent wall function into the method could allow lower resolutions while maintaining high accuracy. Turbulent wall functions for the TLBM have not yet been shown in the literature.

\subsubsection{Heat flux through insulation walls}

An important measurement in order to optimize cooling efficiency of a refrigerated vehicle is the conductive heat flux through the insulation walls. By resolving the insulation walls as a structure of specific materials in our simulations, we are able to calculate the spacial heat transfer in normal direction through the walls for every grid point. Fig. 13 shows the heat influx in the outermost plane of the insulation walls. Note, that we make the assumption of quasi steady state heat transfer through the insulation walls.

High differences between the edges of the refrigerated body with $\dot{Q}=0 \mathrm{~W}$ to $4 \mathrm{~W}$ and the walls with $\dot{Q}=10 \mathrm{~W}$ to $13.6 \mathrm{~W}$ are recognized. Additionally, the wall thickness' influence can be seen as the thinner side walls induce a higher heat flow compared to the thicker ceiling, front and back side.

With Nusselt correlations taken from the VDI-Wärmeatlas [52], an expected value is calculated in order to obtain an estimation of the incoming heat flow of this insulation concept. For this purpose, the correlation for the overflow of planar 


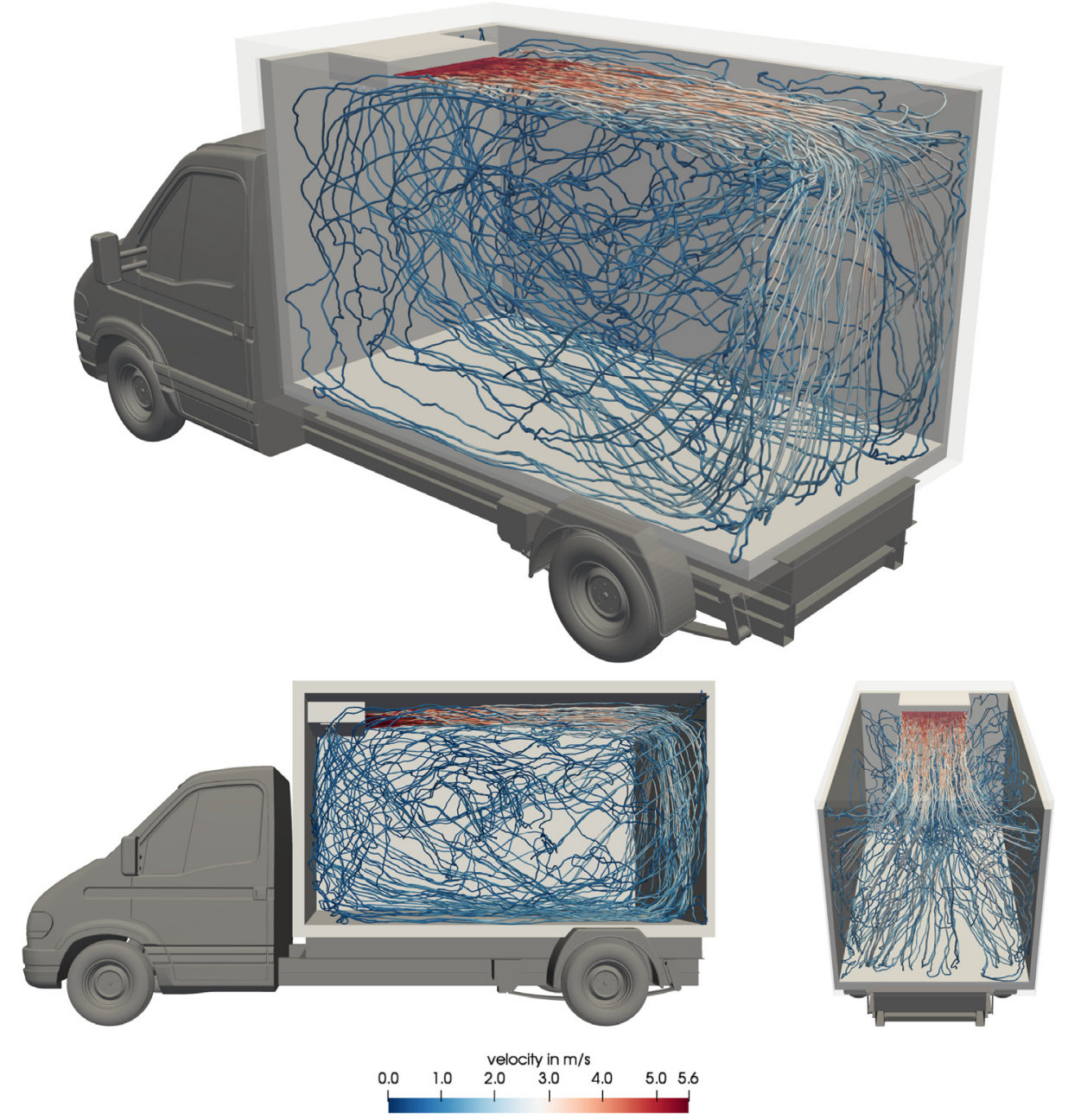

Fig. 11. Streamline representation of the simulated air flow inside the refrigerated vehicle.

Table 5

Experimental measurements and simulated results of the velocity and temperature recordings in the cooling stage after $t=0 \mathrm{~s}$ and $60 \mathrm{~s}$ including absolute deviations for $t=60 \mathrm{~s}$.

\begin{tabular}{|c|c|c|c|c|c|}
\hline \multirow[t]{2}{*}{ time in $\mathrm{s}$} & \multicolumn{2}{|l|}{ Measurement } & \multicolumn{2}{|c|}{ Simulation } & \multirow{2}{*}{$\begin{array}{l}\text { Deviation } \\
60\end{array}$} \\
\hline & 0 & 60 & 0 & 60 & \\
\hline $\mathrm{V} 1 \mathrm{in} \mathrm{m} / \mathrm{s}$ & 0 & $5.0 \pm 0.2$ & 0 & 4.92 & 0.08 \\
\hline $\mathrm{V} 2$ in $\mathrm{m} / \mathrm{s}$ & 0 & $4.3 \pm 0.2$ & 0 & 3.94 & 0.36 \\
\hline $\mathrm{V} 3$ in $\mathrm{m} / \mathrm{s}$ & 0 & $2.2 \pm 0.2$ & 0 & 2.17 & 0.03 \\
\hline $\mathrm{V} 4 \mathrm{in} \mathrm{m} / \mathrm{s}$ & 0 & $1.3 \pm 0.2$ & 0 & 1.22 & 0.08 \\
\hline $\mathrm{T} 1$ in $\mathrm{K}$ & $283.95 \pm 0.20$ & $286.95 \pm 0.30$ & 284.45 & 287.38 & 0.43 \\
\hline $\mathrm{T} 2$ in $\mathrm{K}$ & $283.85 \pm 0.20$ & $286.95 \pm 0.30$ & 284.45 & 287.03 & 0.08 \\
\hline $\mathrm{T} 3$ in $\mathrm{K}$ & $284.15 \pm 0.20$ & $287.15 \pm 0.30$ & 284.45 & 287.19 & 0.04 \\
\hline $\mathrm{T} 4$ in $\mathrm{K}$ & $284.45 \pm 0.20$ & $287.25 \pm 0.30$ & 284.45 & 286.93 & 0.32 \\
\hline $\mathrm{T} 5$ in $\mathrm{K}$ & $285.25 \pm 0.20$ & $287.95 \pm 0.30$ & 284.45 & 287.76 & 0.19 \\
\hline $\mathrm{T} 6$ in $\mathrm{K}$ & $284.55 \pm 0.20$ & $287.35 \pm 0.30$ & 284.45 & 287.31 & 0.04 \\
\hline $\mathrm{T} 7 \mathrm{in} \mathrm{K}$ & $283.65 \pm 0.20$ & $287.45 \pm 0.30$ & 284.45 & 287.49 & 0.04 \\
\hline $\mathrm{T} 8$ in $\mathrm{K}$ & $285.35 \pm 0.20$ & $287.65 \pm 0.30$ & 284.45 & 286.99 & 0.66 \\
\hline $\mathrm{T} 9$ in $\mathrm{K}$ & $285.55 \pm 0.20$ & $287.85 \pm 0.30$ & 284.45 & 288.33 & 0.48 \\
\hline $\mathrm{T} 10$ in $\mathrm{K}$ & $285.65 \pm 0.20$ & $287.85 \pm 0.30$ & 284.45 & 288.68 & 0.83 \\
\hline $\mathrm{T} 11$ in $\mathrm{K}$ & $283.85 \pm 0.20$ & $287.15 \pm 0.30$ & 284.45 & 288.09 & 0.94 \\
\hline $\mathrm{T} 12$ in $\mathrm{K}$ & $284.95 \pm 0.20$ & $287.85 \pm 0.30$ & 284.45 & 287.99 & 0.14 \\
\hline $\mathrm{T} 13$ in $\mathrm{K}$ & $282.55 \pm 0.20$ & $286.85 \pm 0.30$ & 284.45 & 287.28 & 0.43 \\
\hline
\end{tabular}



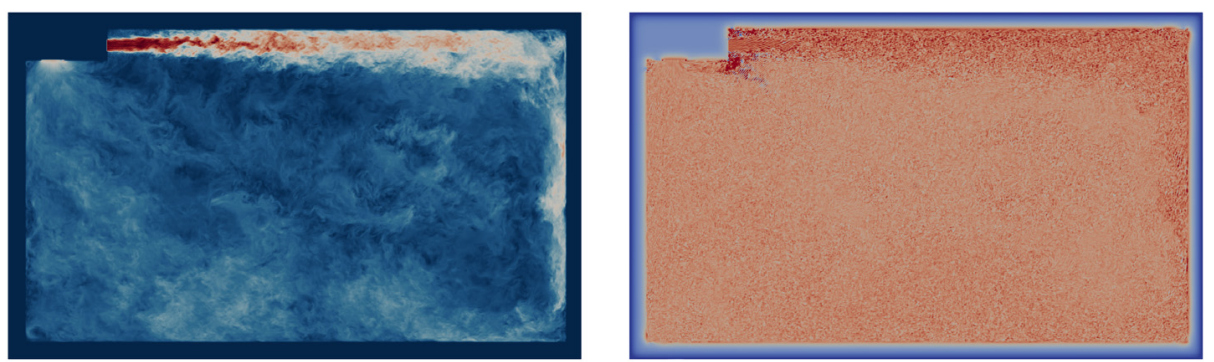

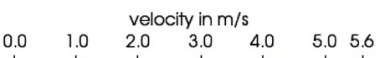

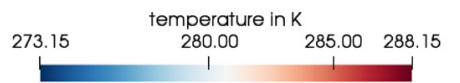

Fig. 12. Velocity and temperature field in $x-y$-plane at $z=0.995 \mathrm{~m}$ of the simulated air and the insulated walls.
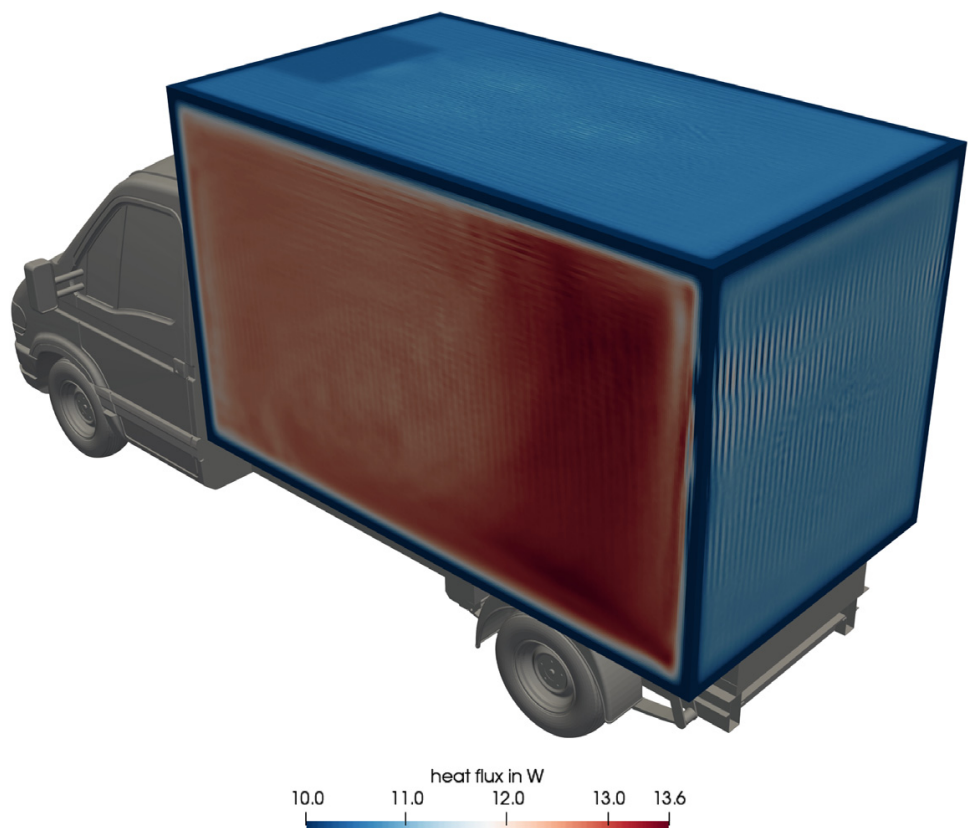

Fig. 13. Heat flux through the insulation of the refrigerated vehicle.

plates is used for the interior space on all internal walls separately and averagely. For each wall, a specific Reynolds number is calculated using the experimentally determined velocities from the validation, a laminar Nusselt number according to (23), as well as a turbulent Nusselt number according to (24).

$$
\begin{aligned}
\mathrm{Nu}_{\text {lam }} & =\left(\frac{2}{1+22 \cdot \frac{v \cdot \rho \cdot c_{p}}{\lambda}}\right)^{\frac{1}{6}} \cdot \sqrt{\operatorname{Re} \cdot \frac{v \cdot \rho \cdot c_{p}}{\lambda}} \\
\mathrm{Nu}_{\text {turb }} & =\frac{0.037 \cdot \mathrm{Re}^{0.8} \cdot \frac{v \cdot \rho \cdot c_{p}}{\lambda}}{1+2.443 \cdot \mathrm{Re}^{-0.1} \cdot\left(\left(\frac{v \cdot \rho \cdot c_{p}}{\lambda}\right)^{\frac{2}{3}}-1\right)} \\
\mathrm{Nu} & =\sqrt{\mathrm{Nu}_{\text {lam }}^{2}+\mathrm{Nu}_{\text {turb }}^{2}}
\end{aligned}
$$

With the help of the wall-specific heat transfer coefficients, an insulation $k_{\text {PUR }}=0.275 \mathrm{~W} /\left(\mathrm{m}^{2} \mathrm{~K}\right)$ for pure hard foam can be obtained, so for a temperature difference of $\Delta T=50 \mathrm{~K}$. A total incoming heat flow of $\dot{Q}_{\text {PUR }}=479 \mathrm{~W}$ is determined. The simulated heat influx through the walls sums up to a value of $\dot{Q}_{\text {PUR }}=458 \mathrm{~W}$ and thus shows a relative deviation from the Nusselt correlation of only $4.38 \%$. The simulation arrives within the deviation of the Nusselt correlation, which has a general discrepancy due to the semi-empirical determination by measured values. 
With the method shown, in contrast to averaged total heat currents, spatially resolved heat flows can be determined, which can be used as a valuable basis for customized insulation optimization at positions of higher heat flow.

\section{Conclusions}

In this paper, we extend a double distribution BGK-based LBM by the Smagorinsky turbulence model for both velocity and temperature distribution functions. This method is found stable for a coarse discretization $(\tau \approx 0.5001)$ with high Re and Ra numbers and accurate for the turbulent natural convection in a square cavity with $R a \leq 10^{10}$. Due to the relatively small resolutions of $y^{+} \approx 2$ used here, the boundary layer is not completely resolved. Therefore, a turbulent wall function implementation should further improve the accuracy of the model for wall bounded turbulence, which will be inspected in a planned publication.

Simulation of the flow field and heat transfer within a given cooling truck shows very good agreement with measurement results. By resolving the truck's insulation walls in a conjugate heat transfer model, the model is able to predict the heat flux through the walls close to Nusselt correlations, but spatially resolved. This allows new insights to the refrigerated vehicle's heat transfer, which is essential for the optimization process of the wall materials and structures considering economic conditions.

Therefore we conclude this simulation model as being able to accurately describe the insulation effect in a refrigerated vehicle with turbulent cold air flows including spatially resolved heat flux through the vehicle's walls.

\section{Acknowledgments}

The authors would like to thank the company Kress Fahrzeugbau GmbH for making available the validation measurements and the german Central Innovation Programme for SMEs for funding this project (ZF4005102CL5). This work was performed on the computational resource ForHLR II funded by the Ministry of Science, Research and the Arts Baden-Württemberg and DFG ("Deutsche Forschungsgemeinschaft").

\section{References}

[1] W. Willems, T. Skottke, Lineare Wärmebrücken in vakuumgedämmten Konstruktionen, Bauphysik 30 (6) (2008) 373-379. http://dx.doi.org/10.1002/ bapi.200810048.

[2] N.J. Smale, J. Moureh, G. Cortella, A review of numerical models of airflow in refrigerated food applications, Int. J. Refrig. 29 (2006) $911-930$. http://dx.doi.org/10.1016/j.ijrefrig.2006.03.019.

[3] M. Tapsoba, J. Moureh, D. Flick, Airflow patterns in a slot-ventilated enclosure partially loaded with empty slotted boxes, Int. J. Heat Fluid Flow 28 (5) (2007) 963-977. http://dx.doi.org/10.1016/j.ijheatfluidflow.2007.03.008. URL http://www.sciencedirect.com/science/article/pii/S0142727X0700030 6.

[4] A. Ambaw, M.A. Delele, T. Defraeye, Q.T. Ho, L.U. Opara, B.M. Nicolaï, P. Verboven, The use of CFD to characterize and design post-harvest storage facilities: Past, present and future, Comput. Electron. Agric. 93 (2013) 184-194.

[5] J. Moureh, M. Tapsoba, D. Flick, Airflow in a slot-ventilated enclosure partially filled with porous boxes: Part I Measurements and simulations in the clear region, Comput. \& Fluids 38 (2)(2009) 194-205. http://dx.doi.org/10.1016/j.compfluid.2008.02.006. URL http://www.sciencedirect.com/science/ article/pii/S0045793008000480.

[6] J. Moureh, M. Tapsoba, D. Flick, Airflow in a slot-ventilated enclosure partially filled with porous boxes: Part II Measurements and simulations within porous boxes, Comput. \& Fluids 38 (2) (2009) 206-220. http://dx.doi.org/10.1016/j.compfluid.2008.02.007. URL http://www.sciencedirect. com/science/article/pii/S0045793008000492.

[7] M. Delele, A. Schenk, E. Tijskens, H. Ramon, B. Nicolaï, P. Verboven, Optimization of the humidification of cold stores by pressurized water atomizers based on a multiscale CFD model, J. Food Eng. 91 (2)(2009) 228-239. http://dx.doi.org/10.1016/j.jfoodeng.2008.08.027. URL http://www.sciencedirect. com/science/article/pii/S0260877408004287.

[8] T. Defraeye, B. Blocken, J. Carmeliet, CFD analysis of convective heat transfer at the surfaces of a cube immersed in a turbulent boundary layer, Int. J. Heat Mass Transfer 53 (1) (2010) 297-308. http://dx.doi.org/10.1016/j.ijheatmasstransfer.2009.09.029. URL http://www.sciencedirect.com/science/ article/pii/S0017931009005109.

[9] S.J. James, C. James, J.A. Evans, Modelling of food transportation systems: a review, Int. J. Refrig. 29 (2006) 947-957. http://dx.doi.org/10.1016/j.ijrefrig. 2006.03.017.

[10] C.P. Tso, S.C.M. Yu, H.J. Poh, P.G. Jolly, Experimental study on the heat and mass transfer characteristics in a refrigerated truck, Int. J. Refrig. 25 (3) (2002) 340-350. http://dx.doi.org/10.1016/S0140-7007(01)00015-9.

[11] S.H. Ho, L. Rosario, M.M. Rahman, Numerical simulation of temperature and velocity in a refrigerated warehouse, Int. J. Refrig. 33 (5) (2010) $1015-1025$. http://dx.doi.org/10.1016/j.ijrefrig.2010.02.010.

[12] X. Hao, Y. Ju, Simulation and analysis on the flow field of the low temperature mini-type cold store, Heat Mass Transfer 47 (7) (2011) 771-775. http://dx.doi.org/10.1007/s00231-011-0764-1.

[13] S. Akdemir, Numerical modelling and experimental validation of a cold store ambient factors, J. Agric. Sci. 21 (2015) 606-619.

[14] H.-m. Hoang, S. Duret, D. Flick, O. Laguerre, Preliminary study of airflow and heat transfer in a cold room filled with apple pallets: Comparison between two modelling approaches and experimental results, Appl. Therm. Eng. 76 (2015) 367-381. http://dx.doi.org/10.1016/j.applthermaleng.2014.11.012.

[15] F. Cardinale, T. De Fazio, P. Grandizio, Numerical and experimental computation of airflow in a transport container, Int. J. Heat Technol. 34 (4) (2016) 734-742. http://dx.doi.org/10.18280/ijht.340426.

[16] S. Getahun, A. Ambaw, M. Delele, C.J. Meyer, U.L. Opara, Analysis of airflow and heat transfer inside fruit packed refrigerated shipping container: Part I - Model development and validation, J. Food Eng. 203 (2017) 58-68. http://dx.doi.org/10.1016/j.jfoodeng.2017.02.010.

[17] J. Fietz, M.J. Krause, C. Schulz, P. Sanders, V. Heuveline, Optimized hybrid parallel lattice Boltzmann fluid flow simulations on complex geometries, in: C. Kaklamanis, T. Papatheodorou, P.G. Spirakis (Eds.), Lecture Notes in Computer Science (Including Subseries Lecture Notes in Artificial Intelligence and Lecture Notes in Bioinformatics), in: Lecture Notes in Computer Science, vol. 7484 LNCS, Springer Berlin Heidelberg, 2012, pp. 818-829. http: //dx.doi.org/10.1007/978-3-642-32820-6_81. 
[18] T. Henn, G. Thäter, W. Dröfler, H. Nirschl, M.J. Krause, Parallel dilute particulate flow simulations in the human nasal cavity, Comput. \& Fluids 124 (2016) 197-207. http://dx.doi.org/10.1016/j.compfluid.2015.08.002.

[19] C.K. Aidun, J.R. Clausen, Lattice-Boltzmann method for complex flows, Annu. Rev. Fluid Mech. 42 (1) (2010) 439-472. http://dx.doi.org/10.1146/ annurev-fluid-121108-145519. arXiv:https://doi.org/10.1146/annurev-fluid-121108-145519.

[20] S. Hou, J. Sterling, S. Chen, G.D. Doolen, A lattice Boltzmann subgrid model for high Reynolds number flows, Fields Inst. Commun. 6 (1994).

[21] C.M. Teixeira, Incorporating turbulence models into the lattice-boltzmann method, Internat. J. Modern Phys. C 09 (08) (1998) 1159-1175. http://dx.doi. org/10.1142/S0129183198001060. arXiv:https://www.worldscientific.com/doi/pdf/10.1142/S0129183198001060. URL https://www.worldscientific. com/doi/abs/10.1142/S0129183198001060.

[22] Y.-H. Dong, P. Sagaut, S. Marie, Inertial consistent subgrid model for large-eddy simulation based on the lattice Boltzmann method, Phys. Fluids 20 (3) (2008) 035104. http://dx.doi.org/10.1063/1.2842379. arXiv:https://doi.org/10.1063/1.2842379.

[23] O. Malaspinas, P. Sagaut, Consistent subgrid scale modelling for lattice Boltzmann methods, J. Fluid Mech. 700 (2012) 514-542. http://dx.doi.org/10. $1017 / \mathrm{jfm} .2012 .155$

[24] A.I. Khan, N. Delbosc, C. Noakes, J. Summers, Real-time flow simulation of indoor environments using lattice Boltzmann method, in: Building Simulation, Tsinghua University Press, 2015.

[25] C. Obrecht, F. Kuznik, L. Merlier, J.-J. Roux, B. Tourancheau, Towards aeraulic simulations at urban scale using the lattice Boltzmann method, Environ. Fluid Mech. 15 (4) (2015) 753-770.

[26] A. Tiftikci, C. Kocar, Investigation of thermal turbulent flow characteristics of wire-wrapped fuel pin bundle of sodium cooled fast reactor in latticeBoltzmann framework, in: 25th International Conference Nuclear Energy for New Europe (NENE), 2016.

[27] X. Yuan, M. Rösler, R. Gritzki, C. Felsmann, Lattice-Boltzmann-Methoden zur Berechnung von Raumluftströmungen, GI - GebäUdetechnik in Wissenschaft \& Praxis 138 (03) (2017) 256-262.

[28] T. Krüger, H. Kusumaatmaja, A. Kuzmin, O. Shardt, G. Silva, M. Viggen, The Lattice Boltzmann Method, Springer, Cham, 2017, p. 694.

[29] A.A. Mohamad, Lattice Boltzmann Method: Fundamentals and Engineering Applications with Computer Codes, Springer, London, 2011 , p. 195.

[30] Z. Guo, C. Zheng, B. Shi, Discrete lattice effects on the forcing term in the lattice Boltzmann method, Phys. Rev. E 65 (2002) 46308 . http://dx.doi.org/ 10.1103/PhysRevE.65.046308.

[31] J. Fröhlich, Large eddy simulation turbulenter Strömungen, Vol. 1, Springer, 2006.

[32] H. Schlichting, K. Gersten, E. Krause, H. Oertel, Boundary-layer Theory, Vol. 7, Springer, 1955.

[33] C. van Treeck, E. Rank, M. Krafczyk, J. Tölke, B. Nachtwey, Extension of a hybrid thermal LBE scheme for large-eddy simulations of turbulent convective flows, Comput. \& Fluids 35 (8-9) (2006) 863-871. http://dx.doi.org/10.1016/j.compfluid.2005.03.006.

[34] S. Dharmarathne, M. Tutkun, G. Araya, L. Castillo, Structures of scalar transport in a turbulent channel, Eur. J. Mech. B Fluids 55 (2016) $259-271$. http://dx.doi.org/10.1016/j.euromechflu.2015.06.010.

[35] J. Latt, B. Chopard, O. Malaspinas, M. Deville, A. Michler, Straight velocity boundaries in the lattice Boltzmann method, Phys. Rev E 77 (5) (2008) 56703. http://dx.doi.org/10.1103/PhysRevE.77.056703.

[36] M. Junk, Z. Yang, Outflow boundary conditions for the lattice Boltzmann method, Prog. Comput. Fluid Dyn. 8 (1-4) (2008) 38-48.

[37] S. Succi, The Lattice Boltzmann Equation: For Fluid Dynamics and Beyond, Oxford University Press, 2001, p. 288. doi: ISBN 0198503989.

[38] J. Wang, M. Wang, Z. Li, A lattice Boltzmann algorithm for fluidsolid conjugate heat transfer, Int. J. Therm. Sci. 46 (3) (2007) 228-234. http://dx.doi. org/10.1016/j.ijthermalsci.2006.04.012.

[39] V. Heuveline, M.J. Krause, OpenLB: Towards an efficient parallel open source library for Lattice Boltzmann fluid flow simulations, in: J.D.A.C. Elster, J. Wasniewski (Eds.), PARA'08 Workshop on State-of-the-Art in Scientific and Parallel Computing, May 13-16, 2008, in: Springer series Lecture Notes in Computer Science (LNCS), no. 6126, 6127, 2011.

[40] M.J. Krause, T. Gengenbach, V. Heuveline, Hybrid parallel simulations of fluid flows in complex geometries: Application to the human lungs, in: M. Guarracino, F. Vivien, J. Traeff, M. Cannatoro, M. Danelutto, A. Hast, F. Perla, A. Knuepfer, B. Di Martino, M. Alexander (Eds.), Proc. $\backslash$ EuroPar, Europ. Conf. Parallel Comput., in: Lecture Notes in Computer Science, vol. 6586, Springer Berlin / Heidelberg, 2010, pp. 209-216. http://dx.doi.org/10.1007/978-3642-21878-1_26.

[41] M.J. Krause, G. Thäter, V. Heuveline, Adjoint-based fluid flow control and optimisation with lattice Boltzmann methods, Comput. Math. Appl. 65 (6) (2013) 945-960. http://dx.doi.org/10.1016/j.camwa.2012.08.007.

[42] A. Mink, G. Thäter, H. Nirschl, M.J. Krause, A 3D Lattice Boltzmann method for light simulation in participating media, J. Comput. Sci. 17 (2016) $431-437$. http://dx.doi.org/10.1016/j.jocs.2016.03.014.

[43] R. Trunk, T. Henn, W. Dörfler, H. Nirschl, M.J. Krause, Inertial dilute particulate fluid flow simulations with an Euler???Euler lattice Boltzmann method, J. Comput. Sci. 17 (2016) 438-445. http://dx.doi.org/10.1016/j.jocs.2016.03.013.

[44] Z. Guo, B. Shi, C. Zheng, A coupled lattice BGK model for the Boussinesq equations, Internat. J. Numer. Methods Fluids 39 (4) (2002) $325-342$.

[45] Y. Peng, C. Shu, Y.T. Chew, Simplified thermal lattice Boltzmann model for incompressible thermal flows, Phys. Rev. E 68 (August) (2003) 1-8. http://dx.doi.org/10.1103/PhysRevE.68.026701.

[46] H.N. Dixit, V. Babu, Simulation of high Rayleigh number natural convection in a square cavity using the lattice Boltzmann method, Int. J. Heat Mass Transfer 49(3-4)(2006) 727-739. http://dx.doi.org/10.1016/j.ijheatmasstransfer.2005.07.046.

[47] G. De Vahl Davis, Natural convection of air in a square cavity: A bench mark numerical solution, Internat. J. Numer. Methods Fluids 3 (3) (1983) 249-264.

[48] N.C. Markatos, Laminar and turbulent natural convection in an enclosed cavity, Int. J. Heat Mass Transfer 27 (5) (1983) 755-772. http://dx.doi.org/10. 1016/0021-9991(84)90123-2.

[49] M. Hortmann, Finite volume multigrid prediction of laminar natural convection: Benchmark solutions, Internat. J. Numer. Methods Fluids 11 (August 1989) (1990) 189-207. http://dx.doi.org/10.1002/fld.1650110206.

[50] F.M. White, Fluid Mechanics, fifth ed., McGraw-Hill Book Company, Boston, 2003, p. 467.

[51] P. Le Quéré, Accurate solutions to the square thermally driven cavity at high Rayleigh number, Comput. \& Fluids 20 (1) (1991) $29-41$.

[52] VDI-Gesellschaft, VDI-Wärmeatlas, eleventh ed., Springer Vieweg, Berlin, Heidelberg, 2013, p. 1512. 
Karlsruher Institut für Technologie

\section{Repository KITopen}

Dies ist ein Postprint/begutachtetes Manuskript.

Empfohlene Zitierung:

Gaedtke, M.; Wachter, S.; Rädle, M.; Nirschl, H.; Krause, M. J.

Application of a lattice Boltzmann method combined with a Smagorinsky turbulence model to spatially resolved heat flux inside a refrigerated vehicle.

2018. Computers and mathematics with applications, 76.

$\underline{10.5445 / / R / 1000088463}$

Zitierung der Originalveröffentlichung:

Gaedtke, M.; Wachter, S.; Rädle, M.; Nirschl, H.; Krause, M. J.

Application of a lattice Boltzmann method combined with a Smagorinsky turbulence model to spatially resolved heat flux inside a refrigerated vehicle.

2018. Computers and mathematics with applications, 76 (10), 2315-2329.

doi:10.1016/j.camwa.2018.08.018 